\title{
An Analysis of Prehistoric Pottery Paint Composition Utilizing Energy Dispersive Spectroscopy.
}

\author{
M. W. Pendleton, ${ }^{*}$ E. A. Ellis, ${ }^{*}$ D. K. Washburn, ${ }^{* *}$ and B. B. Pendleton*** \\ * Microscopy and Imaging Center, Biological Sciences Building West, Room Number 119, Mail \\ Stop 2257, Texas A\&M University, College Station, TX 77843-2257 \\ **Museum of Northern Arizona, 3101 North Fort Valley Road, Flagstaff, AZ 86001 \\ *** Department of Agricultural Sciences, West Texas A\&M University, Box 60998, Canyon, TX \\ 79016-0001
}

Images produced using light microscopy as well as both secondary and backscatter scanning electron microscopy and energy-dispersive spectroscopy (EDS) analyses were produced of painted and unpainted areas of uncoated prehistoric sherd samples. The same samples were then subjected to EDS analysis following carbon coating. In a previous study [1] of paint on southwestern prehistoric pottery, samples were coated with carbon prior to EDS analysis. This study will compare the results of EDS for uncoated and carbon coated samples of both painted and unpainted pottery areas for the same sherd sample.

The dark gray color of the internal section (core area) of the uncoated sherd (Fig. 1) observed using the Pro Scope (Ted Pella Inc., Redding, CA) is caused by incomplete oxidation of organic (carbon) rich clay components during firing [2]. Probably the dark colored core indicates that the firing temperature was relatively low (500 degrees $\mathrm{C}$ ) in an open firing (bonfire) type of situation because the structurally bound water is not present [3]. The dark core also indicates that a short firing time was used for this sherd because firings which last over several hours (as in a kiln) allow the heat and oxidizing gases to penetrate the vessel walls all the way through [4], so the core is no longer a dark color. The temperature and duration of firing has a direct relationship on possible thermal transformations of elements and compounds of the paint applied before firing [5].

The sherd shown in Fig. 1 is an uncoated Anasazi coil-made pottery sample analysed using counts of X-ray signals received from a series of 10 locations on the painted (P) and unpainted (U) surface of the specimen utilizing a Princeton Gamma-Tech (Bruker AXS Inc., Madison, WI) EDS detector with a takeoff angle of 31.0 degrees, count rates of 420 to $675 \mathrm{cps}$ for $100 \mathrm{~s}$ and an estimated probe current of $5.0 \mathrm{nA}$ mounted onto a JEOL 6400 scanning electron microscope operated at an acceleration voltage of $25 \mathrm{keV}$ and a working distance of $15 \mathrm{~mm}$. For this pottery sherd, the weight percent (determined using Spirit EDS analysis software) of iron (Fe) for painted $(\mathrm{P})$ locations is greater than that of the unpainted (U) locations (Fig. 2). These results imply that iron was included in some manner in the composition of the paint applied to this sherd.

\section{References}

[1] J. Stewart and K. Adams, Amer. Antiquity 64 (1999) 675.

[2] J. Henderson, The Science and Archaeology of Materials: An Investigation of Inorganic Materials, Routledge, New York, 2000.

[3] P. M. Rice, Pottery Analysis: A Sourcebook, University of Chicago Press, Chicago, 1987.

[4] A. Gibson and A. Woods, Prehistoric Pottery for the Archaeologist, 2nd ed., Leicester University Press, Washington, 1997.

[5] J. van der Weerd, et al., J. Arch. Sci. 31 (2004) 1429. 


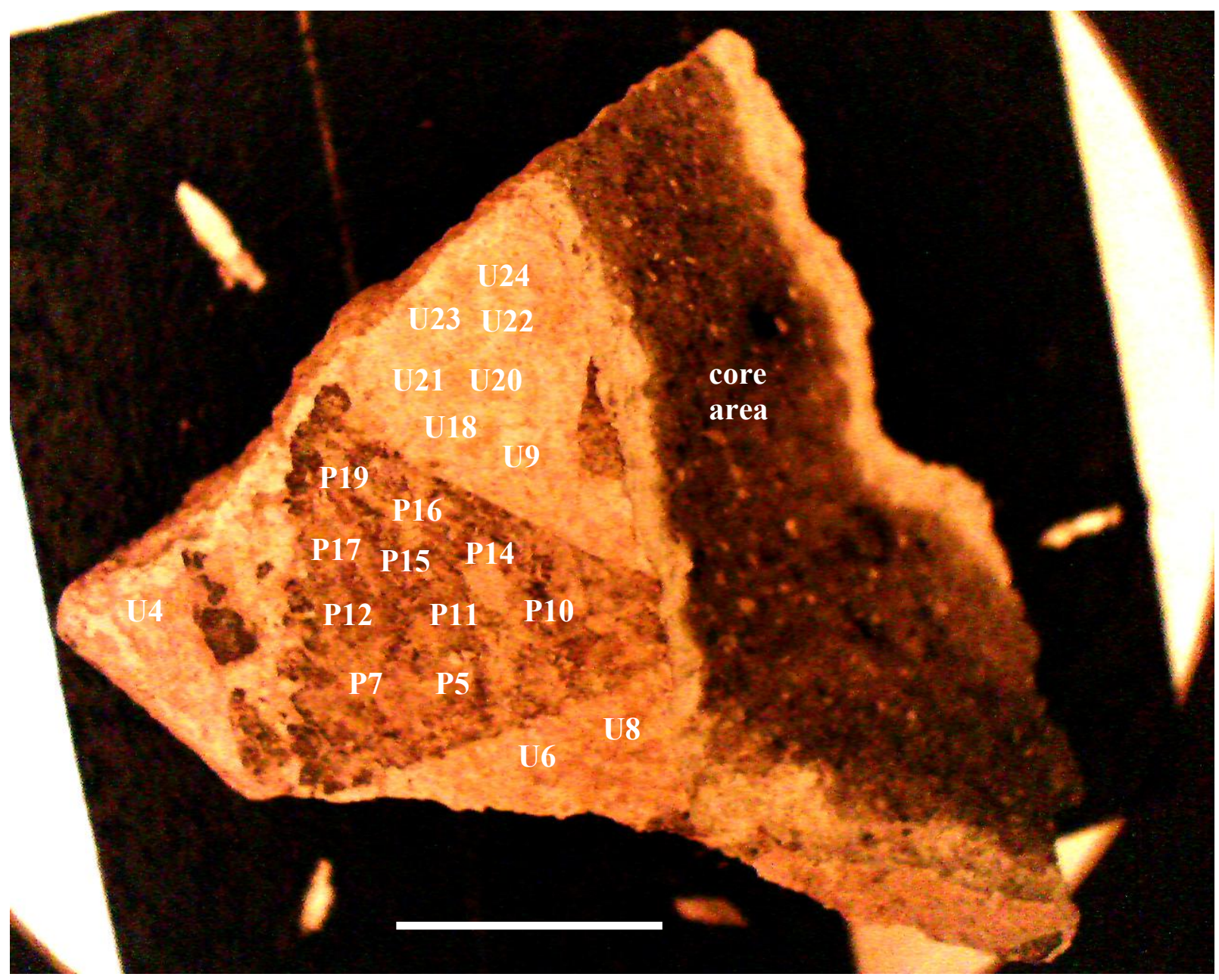

Fig. 1. Locations of painted (P) and unpainted (U) EDS analyses on sherd. Scale bar $=5 \mathrm{~mm}$.

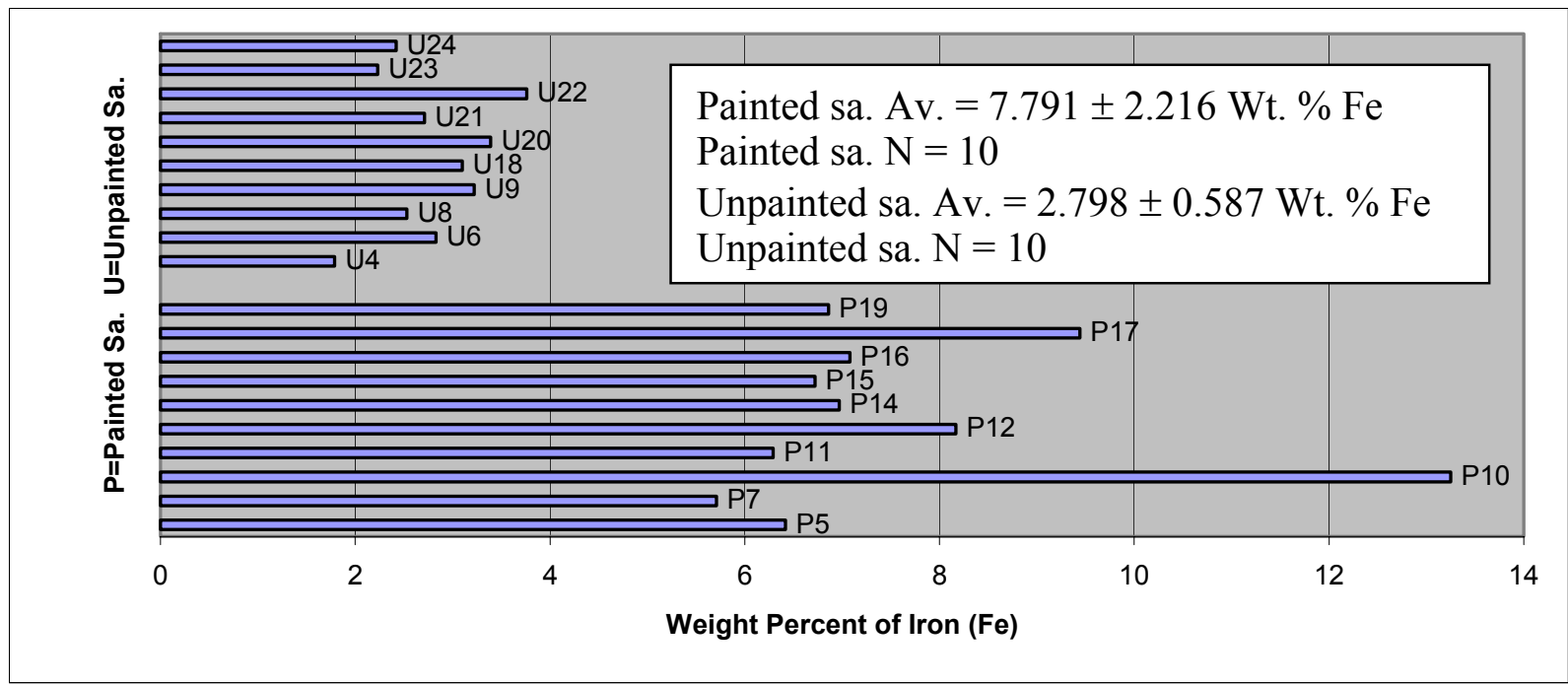

Fig. 2. Weight percents of iron for 10 painted (P) and 10 unpainted (U) locations on sherd. 